\title{
Effects of Religious vs. Conventional Cognitive-Behavioral Therapy on Inflammatory Markers and Stress Hormones in Major Depression and Chronic Medical Illness: A Randomized Clinical Trial
}

\author{
Lee S. Berk ${ }^{1,2,3}$, Denise L. Bellinger ${ }^{2}$, Harold G. Koenig3,4,5,6*, Noha Daher ${ }^{1,7}$, \\ Michelle J. Pearce ${ }^{3,4,8}$, Clive J. Robins ${ }^{4,9}$, Bruce Nelson ${ }^{10}$, Sally F. Shaw ${ }^{10}$, \\ Harvey Jay Cohen ${ }^{3,5}$, Michael B. King11 \\ ${ }^{1}$ Allied Health Studies, School of Allied Health Professions, Loma Linda University, Loma Linda, USA \\ ${ }^{2}$ Department of Pathology and Human Anatomy, School of Medicine, Loma Linda University, Loma Linda, USA \\ ${ }^{3}$ Center for Spirituality, Theology and Health, Duke University, Durham, USA \\ ${ }^{4}$ Department of Psychiatry and Behavioral Sciences, Duke University Medical Center, Durham, USA \\ ${ }^{5}$ Department of Medicine, Duke University Medical Center, Durham, USA \\ ${ }^{6}$ Department of Medicine, King Abdulaziz University, Jeddah, Saudi Arabia \\ ${ }^{7}$ Epidemiology, Biostatistics, and Population Medicine, School of Public Health, Loma Linda University, \\ Loma Linda, USA \\ ${ }^{8}$ School of Medicine, University of Maryland, Baltimore, USA \\ ${ }^{9}$ Department of Psychology and Neuroscience, Duke University Medical Center, Durham, USA \\ ${ }^{10}$ Department of Research, Glendale Adventist Medical Center, Glendale, USA \\ ${ }^{11}$ Division of Psychiatry, Faculty of Brain Sciences, University College, London, UK \\ Email: ${ }^{*}$ Harold.Koenig@duke.edu
}

Received 23 April 2015; accepted 29 May 2015; published 1 June 2015

Copyright @ 2015 by authors and Scientific Research Publishing Inc.

This work is licensed under the Creative Commons Attribution International License (CC BY).

http://creativecommons.org/licenses/by/4.0/

(c) (i) 0pen Access

\section{Abstract}

Background: Depressive disorder is often accompanied by physiological changes that may adversely affect the course of medical illness, including an increase in pro-inflammatory cytokines. Methods: We examine the effects of religious cognitive behavioral therapy (RCBT) vs. conventional CBT (CCBT) on pro-/anti-inflammatory indicators and stress hormones in 132 individuals with major depressive disorder (MDD) and chronic medical illness who were recruited into a multi-site randomized clinical trial. Biomarkers (C-reactive protein and pro-inflammatory cytokines TNF- $\alpha$,

*Corresponding author.

How to cite this paper: Berk, L.S., et al. (2015) Effects of Religious vs. Conventional Cognitive-Behavioral Therapy on Inflammatory Markers and Stress Hormones in Major Depression and Chronic Medical IIIness: A Randomized Clinical Trial. Open Journal of Psychiatry, 5, 238-259. http://dx.doi.org/10.4236/ojpsych.2015.53028 
IL-1 $\beta$, IFN- $\gamma$, IL-6, IL-12-p70), anti-inflammatory cytokines (IL1ra, IL-4, IL-10), and stress hormones (urinary cortisol, epinephrine, norepinephrine) were assessed at baseline, 12 weeks, and 24 weeks. Differential effects of baseline religiosity on treatment response were also examined, along with effects of religiosity on changes in biomarkers over time independent of treatment group. Biomarker levels were log transformed where possible to normalize distributions. Mixed models were used to examine trajectories of change. Results: CRP increased and IL-4, IL-10, and epinephrine decreased over time, mostly in the opposite direction expected (except epinephrine). No significant difference between RCBT and CCBT was found on average trajectory of change in any biomarkers. Religiosity interacted with treatment group in effects on IL-6, such that CCBT was more effective than RCBT in lowering IL-6 in those with low religiosity whereas RCBT appeared to be more effective than CCBT in those with high religiosity. Higher baseline religiosity also tended to predict an increase in pro-inflammatory cytokines INF- $\gamma$ and IL-12 (p70) and urinary cortisol over time. Conclusions: RCBT and CCBT had similar effects on stress biomarkers. CCBT was more effective in reducing IL-6 levels in those with low religiosity, whereas RCBT tended to be more effective in those with high religiosity. Unexpectedly, higher baseline religiosity was associated with an increase in several stress biomarkers.

\title{
Keywords
}

\author{
Cognitive Behavioral Therapy, Religion, Depression, Inflammation, Immune Function, Stress \\ Hormones
}

\section{Introduction}

Depressive disorder is often accompanied by physiological changes that may adversely affect the course of medical illness, including an increase in pro-inflammatory cytokines such as IL-6, IL-12, IFN- $\gamma$, IL-1, and TNF- $\alpha$ [1]-[3], a reduction in anti-inflammatory cytokines such as IL-4 and IL-10 [4] [5], and an increase in stress hormones [6]. Such physiological changes may increase risk of infection [7], vulnerability to and course of malignancy [8] [9], and may lead to inflammatory disorders [10]. The association between depressive disorder and changes in immune and endocrine function is a complex one, though, and this relationship has been argued to be bi-directional in effect [11]. Severe depression may influence levels of inflammation and stress hormones, as inflammation and altered stress hormones can lead to sickness behaviors that resemble depression or lead to depression [4].

The abnormal changes in immunity, inflammation, and stress hormone levels associated with depression have been shown in clinical trials to return back towards normal with a variety of treatments, including antidepressant drug therapy [3] [12] [13], electroconvulsive therapy (TNF- $\alpha$ ) [2], and especially, a wide range of psychological interventions [14]-[17].

Religious involvement is widespread in the United States (US) population [18] [19], and religion is often used to cope with psychological stress [20] and medical illness in particular [21]. Religiosity has been reported to prevent the development of depression, increase the speed of depression remission, and may help persons to cope with depression in the setting of chronic medical illness [22]-[24]. Religious involvement has also been associated with lower levels of pro-inflammatory markers such as C-reactive protein (CRP) and IL-6 [25]-[27], higher levels of anti-inflammatory markers such as IL-1ra [28], and lower levels of stress hormones such as cortisol and norepinephrine [29]-[34] in cross-sectional studies. Spiritual interventions have also been shown to alter pro-/anti-inflammatory cytokine levels [35] [36], decrease cortisol [36]-[38], and lower specific catecholamines such as epinephrine and norepinephrine [39] [40].

In a recent clinical trial, we found little difference in outcome between religious cognitive behavioral therapy (RCBT) and conventional CBT (CCBT) in the treatment of major depressive disorder (MDD) in patients with chronic medical illness. In a secondary analysis, there was evidence that outcomes were better for more religious people who received RCBT (possibly due to better treatment adherence) [41]. Thus, we decided to compare the effects of RCBT vs. CCBT on changes in immune/inflammatory biomarker and stress hormone levels during treatment in this same cohort. 


\section{Hypotheses}

The present analysis examines the effects of religious vs. conventional CBT (RCBT vs. CCBT) on stress biomarkers (inflammation and stress hormones) over 24 weeks during the course of a randomized clinical trial focused on treating persons with MDD and chronic medical illness who were at least somewhat religious or spiritual. We hypothesized that:

1) RCBT will be more effective than CCBT in a) reducing pro-inflammatory cytokines; b) increasing antiinflammatory cytokines; and c) reducing stress hormones (12-hour urinary cortisol, epinephrine, and norepinephrine);

2) RCBT will be more effective in lowering pro-inflammatory cytokines and stress hormones and increasing anti-inflammatory cytokines in those who are more religious; and

3) Baseline religiosity will predict a decrease in pro-inflammatory cytokines and stress hormones and an increase in anti-inflammatory cytokines over time independent of treatment group.

\section{Methods}

The methodology involved in the randomized clinical trial has been described in detail elsewhere [41], although we summarize important aspects here. We recruited persons aged 18 to 85 into a multi-site randomized clinical trial (Durham County, North Carolina, and Los Angeles County, California). Potential participants were screened over the telephone, and if they passed this initial screen, were invited to come to the hospital for further screening after signing an informed consent form. Inclusion criteria were 1) one or more chronic medical illnesses present for 6 months or longer; 2) a DSM-IV diagnosis of major depressive disorder made by a structured psychiatric interview, the MINI Neuropsychiatric Interview [42], which follows DSM-IV criteria; 3) mild to moderately severe depressive symptoms (10 to 40 on the 21-item Beck Depression Inventory [BDI-II, which ranges from 0 to 63]) [43]; and 4) religion or spirituality at least somewhat important, assessed by the question "How important is religion/spirituality in your daily life?" ("somewhat important" or more was required). Exclusion criteria were 1) having significant cognitive impairment based on the brief Mini-Mental Stated Exam [44]; 2) having received psychotherapy within the past two months; 3) having a diagnosis of psychotic disorder, substance abuse, or posttraumatic stress disorder (PTSD) on the MINI within the past year; 4) having any history of bipolar disorder (MINI); 5) any active suicidal thoughts (MINI); and 6) having a diagnosis of human immunodeficiency virus/acquired immunodeficiency syndrome (HIV/AIDS), autoimmune diseases, endocrine disorders, a prognosis of less than 6 months, or taking immunosuppressant drugs, given the immune analyzes planned for this report. Those who fulfilled inclusion criteria and had no exclusion criteria then completed a baseline evaluation and were randomized to treatment group by an external group. Interviewers underwent extensive training to ensure that they remained blind to treatment group throughout the study. Duke University Medical Center and Glendale Adventist Medical Center institutional review boards approved the study.

\subsection{Interventions}

Eight master's level cognitive behavioral therapists conducted the therapy (four delivering CCBT and four delivering RCBT). The intervention consisted of ten 50-minute sessions administered over 12 weeks delivered remotely by telephone (94\%); the remaining sessions were conducted by Skype (5\%) or online using instant messaging (1\%). Remote delivery of therapy was chosen to reduce the effort necessary for those with chronic medical illness to participate.

Conventional CBT was a manual-based intervention following CBT for depression as described by Aaron Beck, focused on altering dysfunctional cognitions and reducing depression-inducing behaviors [45]. If religious issues were brought up during the therapy, the therapist gently redirected the client to more secular ways of approaching the issue.

Religiously integrated CBT was also a manual-based intervention developed specifically for this study. Five version of RCBT were developed so that they would match the religion of the client. First, a Christian version of the CCBT manual was developed [46], and then adapted for Buddhist, Hindu, Muslim, and Jewish clients. University faculty from Jewish, Muslim, Hindu, and Buddhist religious traditions with experience integrating religious beliefs into CBT guided the development of the manuals and workbooks [47]. The faculty also helped to supervise therapists when a client from a particular faith background was enrolled into the study. 
There was considerable overlap between the two forms of CBT. Both integrated "spiritual” content into therapy, focusing on forgiveness, gratefulness, altruistic behaviors, and engagement in social activities. Mindfulness meditation was included in CCBT to match the meditative practices that were part of the RCBT intervention. In fact, the only difference between CCBT and RCBT interventions was that RCBT attempted to integrate the client's religious beliefs into the therapy and use them to motivate changes in dysfunctional cognitions and behaviors.

\subsection{Measures}

Biomarkers. The methods for assessing indicators of inflammation and measures of stress hormones have been described in full elsewhere [34]. In summary, serum inflammatory markers (TNF- $\alpha$, IFN- $\gamma$, IL-1 $\beta$, IL-4, IL-6, IL-10, IL-12 p70) were measured using Millipore’s multiplexed high sensitivity cytokine magnetic bead-based immunoassay kits (Milliplex cat \#HSTCMAG-28SK, EMD Millipore, Billerica, MA). IL-1ra was run using the Milliplex Human Cytokine kit (Hcytomag-60K). Intra- and inter-assay coefficients of variation (CV) were $<6 \%$ and $<20 \%$ for all cytokines, respectively. All samples were run in duplicate along with duplicate standards that were used to generate a standard curve, and samples were repeated if the CV between the duplicates was greater than $15 \%$.

Serum CRP was measured using enzyme-linked immunosorbent assay (ELISA) kits from Assaypro, St Charles, MO), which have a minimal detection of $\sim 0.25 \mathrm{ng} / \mathrm{ml}$ and an intra- and inter-assay CV of $5.0 \%$ and 7.1\%, respectively. Cortisol concentrations were measured in 12-h overnight urine samples using ELISA kits (Enzo Life Sciences International Inc., Plymouth Meeting, PA) that had a lower limit of detection of $333 \mathrm{pg} / \mathrm{ml}$, and intra-and inter-assay CV of $10.5 \%$ and $13.4 \%$, respectively. Cortisol levels were normalized for urine volume using creatinine levels determined by parametric kits that employed the Jaffe reaction (R \& D Systems, Minneapolis, MN; minimal detection of $0.01 \mathrm{mg} / \mathrm{dL}$ and intra- and inter-assay CV of 3.5\% and $4.0 \%$, respectively). All samples were run in duplicate along with duplicate standards that were used to generate a standard curve. If the coefficient of variance between the duplicates was greater than $15 \%$, the assay was repeated for that sample.

Twelve-hour urinary catecholamines (epinephrine and norepinephrine) were determined by high performance liquid chromatography with coulochem detection (HPLC-CD). They were analyzed using EZChrom Elite Software (Scientific Software Inc. Pleasanton, CA). Concentrations were determined based on standards of known concentrations (200 ng/ml) of norepinephrine, epinephrine, and dopamine and expressed as $\mu \mathrm{g} / \mathrm{g}$ creatinine to normalize for urine volume.

Religiosity. Standard single item measures of self-rated religiosity, organizational religious activity (attendance at services), and private religious activity (frequency of prayer, meditation, and scripture study) were administered [48], along with multi-item measures of intrinsic religiosity [49] and daily spiritual experiences [50]. To increase the power of the analysis for the primary hypotheses, religious variables were combined into an overall 29-item religiosity measure by summing self-rated religiosity, public and private religious activity, daily spiritual experiences, and intrinsic religiosity (range 44 - 153); alpha for the scale was 0.95.

Demographics and physical health. Demographic characteristics assessed were age and education (continuous in years), gender, race, and marital status. The 12-item Duke Activity Status Index (DASI) [51] was used to measure physical functioning across domains for physical and instrumental activities of daily living (range 12 36, with higher scores indicating better function). Medical co-morbidity was assessed using the Charlson Comorbidity Index, which provides a count of and severity ratings for ICD-10 medical illnesses [52]. Severity of overall medical illness was determined using the Cumulative Illness Rating Scale [53].

\subsection{Statistical Analysis}

Descriptive statistics were used to compare the two treatment groups at baseline (Table 1). Given concern over their outlier status, biomarker values more than three standard deviations (97.8\% of the normal distribution) above the median value were omitted from analyses. This was done for approximately $3 \%$ of values and involved 42 participants assessed over the three time points. Since none of the biomarkers were normally distributed, they were log transformed to normalize their values; because log transformations did not normalize IL-12-p70 and IL-4, analyses were performed on original values. 
Table 1. Baseline characteristics of treatment groups.

\begin{tabular}{|c|c|c|}
\hline & ССВT & RCBT \\
\hline & $(\mathrm{n}=67)$ & $(\mathrm{n}=65)$ \\
\hline \multicolumn{3}{|l|}{ Demographics } \\
\hline Gender, female $(\%, \mathrm{~N})^{1}$ & $65.7(44)$ & $72.3(47)$ \\
\hline Age, years (mean, SD) & $52.5(13.7)$ & $50.7(13.3)$ \\
\hline Race, white Caucasian $(\%, \mathrm{~N})$ & $58.2(39)$ & $47.7(31)$ \\
\hline Education, years (mean, SD) & $15.2(3.2)$ & $15.0(3.5)$ \\
\hline Marital status, married $(\%, \mathrm{~N})$ & $41.8(28)$ & $36.9(24)$ \\
\hline Center, Duke $(\%, \mathrm{~N})$ & $47.8(32)$ & $46.2(30)$ \\
\hline \multicolumn{3}{|l|}{$\underline{\text { Religious characteristics }}$} \\
\hline \multicolumn{3}{|l|}{ Affiliation (\%, N) } \\
\hline Christian & $92.5(62)$ & $83.1(54)$ \\
\hline Buddhist & $4.5(3)$ & $6.2(4)$ \\
\hline Jewish & $1.5(1)$ & $6.2(4)$ \\
\hline Muslim & $0(0)$ & $1.5(1)$ \\
\hline Hindu & $1.5(1)$ & $3.1(2)$ \\
\hline Importance, very (\%, N) & $44.8(30)$ & $49.2(32)$ \\
\hline Attendance, $\geq$ weekly (\%, N) & $41.8(28)$ & $43.1(28)$ \\
\hline Prayer, daily or more $(\%, \mathrm{~N})$ & $38.8(26)$ & $35.4(23)$ \\
\hline Intrinsic religiosity (mean, SD) & $34.5(8.3)$ & $35.2(8.4)$ \\
\hline Spiritual experiences (mean, SD) & $57.5(16.1)$ & $57.7(15.9)$ \\
\hline Overall baseline religiosity (mean, SD) & $102.6(25.6)$ & $103.3(25.2)$ \\
\hline \multicolumn{3}{|l|}{ Depression } \\
\hline Beck Depression Scale (mean, SD) & $25.8(9.2)$ & $24.8(7.6)$ \\
\hline Depression onset, $<12$ months (\%, N) & $70.2(47)$ & $73.9(48)$ \\
\hline \multicolumn{3}{|l|}{ Physical illness severity } \\
\hline Co-morbidity score (mean, SD) & $2.7(2.4)$ & $2.1(2.0)$ \\
\hline Physical functioning (mean, SD) & $29.1(5.6)$ & $28.7(5.9)$ \\
\hline Illness severity (mean, SD) & $6.5(4.7)$ & $7.1(5.7)$ \\
\hline
\end{tabular}

${ }^{1}$ Column \% (N); CCBT = conventional CBT; RCBT = religious CBT. Table adapted from Koenig et al. (2015) [41].

In bivariate analyses, mean levels of biomarkers were compared between treatment groups at baseline, 12-week follow-up, and 24-week follow-up using the Student's t-test (Table 2). Growth curve modeling using random intercept and slope (mixed effect regression models) examined the effect of the treatment (RCBT vs. CCBT) on trajectory of change of individual inflammatory markers and stress hormones from baseline to 24-week follow-up (Table 3). This method allowed for participants with data for at least one time point to be included in the analysis and the retention of participants with missing data. The model included the fixed effects of group, time, and group by time interaction. The primary analysis was an intention-to-treat (ITT) analysis that included all randomized participants; analyses were repeated using a per-protocol (PP) method that included 
Table 2. Means (SD) of inflammatory markers and stress hormones at baseline, 12 weeks and 24 weeks by treatment group.

\begin{tabular}{|c|c|c|c|c|}
\hline PRO-INFLAMMATORY & CCBT & RCBT & Difference & $\mathbf{p}^{2}$ \\
\hline $\mathrm{CRP}(\mathrm{mg} / \mathrm{L})$ & Mean $(\mathrm{SD})^{1}$ & Mean (SD) & Mean $(95 \%$ CI) & \\
\hline \multicolumn{5}{|l|}{ Intention-to-treat analysis } \\
\hline Baseline (63 vs. 64$)^{3}$ & $6.52(6.64)$ & $5.92(6.52)$ & 0.61 ( -1.70 to 2.92$)$ & 0.649 \\
\hline 12-week (46 vs. 42) & $5.44(6.67)$ & $7.88(10.72)$ & $-2.45(-6.29$ to 1.39$)$ & 0.287 \\
\hline 24-week (30 vs. 24) & $8.03(10.75)$ & $8.09(6.87)$ & $-0.06(-4.91$ to 4.78$)$ & 0.422 \\
\hline \multicolumn{5}{|l|}{ Per-protocol analysis } \\
\hline Baseline (43 vs. 46) & $6.64(6.72)$ & $6.10(6.40)$ & 0.54 ( -2.23 to 3.30$)$ & 0.624 \\
\hline 12-week (43 vs. 39) & $5.34(6.67)$ & $7.70(10.6)$ & $-2.36(-6.32$ to 1.60$)$ & 0.665 \\
\hline 24-week (28 vs. 22) & $8.11(11.03)$ & $8.16(6.94)$ & $-0.05(-5.20$ to 5.10$)$ & 0.410 \\
\hline \multicolumn{5}{|l|}{ TNF- $\alpha(\mathrm{pg} / \mathrm{ml})$} \\
\hline \multicolumn{5}{|l|}{ Intention-to-treat analysis } \\
\hline Baseline (63 vs. 61) & $6.92(3.07)$ & $7.05(3.76)$ & $-0.13(-1.35$ to 1.09$)$ & 0.842 \\
\hline 12-week (44 vs. 42) & $6.81(2.20)$ & $6.39(2.46)$ & $0.42(-0.58$ to 1.41$)$ & 0.286 \\
\hline 24-week (29 vs. 27) & $6.46(2.18)$ & $6.94(5.01)$ & $-0.48(-2.60$ to 1.65$)$ & 0.847 \\
\hline \multicolumn{5}{|l|}{ Per-protocol analysis } \\
\hline Baseline (45 vs. 43) & $6.73(2.31)$ & $6.27(2.33)$ & $0.46(-0.52$ to 1.44$)$ & 0.313 \\
\hline 12-week (41 vs. 38) & $6.88(2.24)$ & $6.30(2.55)$ & 0.58 ( -0.49 to 1.66$)$ & 0.172 \\
\hline 24-week (27 vs. 24) & $6.56(2.23)$ & $6.85(5.27)$ & -0.29 ( -2.65 to 2.07$)$ & 0.613 \\
\hline \multicolumn{5}{|l|}{ IL-1 $\beta(p g / m l)$} \\
\hline \multicolumn{5}{|l|}{ Intention-to-treat analysis } \\
\hline Baseline (62 vs. 62) & $1.28(1.07)$ & $1.71(1.89)$ & $-0.43(-0.98$ to 0.12$)$ & 0.570 \\
\hline 12-week (44 vs. 43) & $1.31(1.11)$ & $1.25(1.14)$ & $0.06(-0.42$ to 0.54$)$ & 0.245 \\
\hline 24-week (29 vs. 27) & $1.41(1.93)$ & $1.17(1.21)$ & 0.25 ( -0.61 to 1.10$)$ & 0.302 \\
\hline \multicolumn{5}{|l|}{ Per-protocol analysis } \\
\hline Baseline (44 vs. 44) & $1.11(0.91)$ & $1.46(1.44)$ & -0.34 ( -0.85 to 0.17$)$ & 0.728 \\
\hline 12-week (40 vs. 39) & $1.28(1.14)$ & $1.30(1.18)$ & $-0.03(-0.54$ to 0.49$)$ & 0.360 \\
\hline 24-week (27 vs. 24) & $1.42(2.00)$ & $1.19(1.28)$ & 0.23 ( -0.71 to 1.17$)$ & 0.318 \\
\hline \multicolumn{5}{|l|}{ IFN- $\gamma(\mathrm{pg} / \mathrm{ml})$} \\
\hline \multicolumn{5}{|l|}{ Intention-to-treat analysis } \\
\hline Baseline (64 vs. 62) & $9.91(8.12)$ & $9.41(9.11)$ & 0.50 (-2.54 to 3.54$)$ & 0.434 \\
\hline 12-week (44 vs. 42) & $9.27(7.65)$ & $9.22(8.40)$ & 0.05 (-3.39 to 3.49$)$ & 0.381 \\
\hline 24-week (29 vs. 27) & $7.90(5.46)$ & $7.07(5.58)$ & 0.84 ( -2.12 to 3.80$)$ & 0.241 \\
\hline \multicolumn{5}{|l|}{ Per-protocol analysis } \\
\hline Baseline (45 vs. 44) & $8.45(6.76)$ & $9.04(9.01)$ & -0.59 (-3.94 to 2.76$)$ & 0.694 \\
\hline 12-week (41 vs. 38) & $8.94(6.78)$ & $9.57(8.74)$ & $-0.63(-4.12$ to 2.87$)$ & 0.421 \\
\hline 24-week (27 vs. 24) & $8.28(5.46)$ & $7.34(5.81)$ & 0.95 ( -2.23 to 4.12$)$ & 0.209 \\
\hline
\end{tabular}




\section{Continued}

\begin{tabular}{|c|c|c|c|c|}
\hline IL-6 (pg/ml) & & & & \\
\hline \multicolumn{5}{|l|}{ Intention-to-treat analysis } \\
\hline Baseline (64 vs. 62) & $2.84(2.57)$ & $2.56(2.49)$ & 0.28 ( -0.61 to 1.17$)$ & 0.900 \\
\hline 12-week (45 vs. 41 ) & $2.40(1.78)$ & $2.13(1.45)$ & 0.27 ( -0.43 to 0.97$)$ & 0.997 \\
\hline 24-week (29 vs. 26) & $2.03(2.06)$ & $2.00(1.87)$ & $0.03(-1.04$ to 1.10$)$ & 0.413 \\
\hline \multicolumn{5}{|l|}{ Per-protocol analysis } \\
\hline Baseline (45 vs. 44) & $2.23(2.06)$ & $2.19(2.20)$ & $0.04(-0.85$ to 0.94$)$ & 0.820 \\
\hline 12-week (42 vs. 37 ) & $2.36(1.79)$ & $2.12(1.49)$ & 0.24 ( -0.50 to 0.99$)$ & 0.978 \\
\hline 24-week (27 vs. 23) & $2.05(2.12)$ & 1.96 (1.99) & $0.09(-1.09$ to 1.26$)$ & 0.505 \\
\hline \multicolumn{5}{|l|}{ IL-12 p70 (pg/ml) } \\
\hline \multicolumn{5}{|l|}{ Intention-to-treat analysis } \\
\hline Baseline (64 vs. 62) & $2.99(2.28)$ & $2.95(3.85)$ & $0.04(-1.08$ to 1.16$)$ & 0.946 \\
\hline 12-week (43 vs. 41 ) & $2.54(1.96)$ & $2.24(1.52)$ & $0.30(-0.47$ to 1.06$)$ & 0.439 \\
\hline 24-week (29 vs. 27) & $1.99(1.30)$ & $1.85(1.33)$ & $0.14(-0.56$ to 0.85$)$ & 0.682 \\
\hline \multicolumn{5}{|l|}{ Per-protocol analysis } \\
\hline Baseline (45 vs. 44 ) & $2.50(1.98)$ & $2.46(2.20)$ & 0.04 ( -0.84 to 0.92$)$ & 0.928 \\
\hline 12-week (40 vs. 37 ) & $2.45(1.83)$ & $2.31(1.55)$ & $0.14(-0.63$ to 0.91$)$ & 0.719 \\
\hline 24-week (27 vs. 24) & $2.03(1.32)$ & $1.81(1.41)$ & $0.22(-0.54$ to 0.99$)$ & 0.563 \\
\hline \multicolumn{5}{|c|}{ ANTI-INFLAMMATORY } \\
\hline \multicolumn{5}{|l|}{ IL-1ra (pg/ml) } \\
\hline \multicolumn{5}{|l|}{ Intention-to-treat analysis } \\
\hline Baseline (64 vs. 63) & 33.78 (70.89) & $39.10(71.71)$ & $-5.32(-30.36$ to 19.73$)$ & 0.630 \\
\hline 12-week (46 vs. 41) & 25.65 (40.57) & 21.43 (35.93) & $4.22(-12.20$ to 20.65$)$ & 0.098 \\
\hline 24-week (30 vs. 24) & $23.43(27.18)$ & $47.52(76.74)$ & -24.09 (-57.77 to 9.58$)$ & 0.474 \\
\hline \multicolumn{5}{|l|}{ Per-protocol analysis } \\
\hline Baseline (46 vs. 46 ) & $23.62(38.27)$ & $48.42(81.50)$ & $-24.80(-51.32$ to 1.72$)$ & 0.974 \\
\hline 12-week (43 vs. 38 ) & $26.52(41.75)$ & $22.21(37.22)$ & 4.30 (-13.29 to 21.89$)$ & 0.09 \\
\hline 24-week (28 vs. 22) & $24.63(27.74)$ & $51.16(79.27)$ & -26.53 ( -26.53 to 62.96$)$ & 0.440 \\
\hline \multicolumn{5}{|l|}{ IL-4 (pg/ml) } \\
\hline \multicolumn{5}{|l|}{ Intention-to-treat analysis } \\
\hline Baseline (63 vs. 58) & $12.72(12.72)$ & 12.33 (11.89) & $0.38(-4.06$ to 4.83$)$ & 0.865 \\
\hline 12-week (43 vs. 43 ) & $9.95(8.46)$ & 11.07 (11.25) & $-1.12(-5.39$ to 3.15$)$ & 0.605 \\
\hline 24-week (28 vs. 27) & $6.77(6.46)$ & $7.15(10.42)$ & $-0.39(-5.12$ to 4.35$)$ & 0.870 \\
\hline \multicolumn{5}{|l|}{ Per-protocol analysis } \\
\hline Baseline (45 vs. 43) & $11.47(10.34)$ & $11.51(11.92)$ & -0.04 ( -4.76 to 4.68$)$ & 0.986 \\
\hline 12-week (40 vs. 39) & $9.53(8.42)$ & 11.75 (11.55) & -2.22 (-6.74 to 2.30$)$ & 0.437 \\
\hline 24-week (26 vs. 24) & $6.73(6.67)$ & $7.84(10.86)$ & -1.10 (-6.31 to 4.11$)$ & 0.671 \\
\hline
\end{tabular}




\section{Continued}

\begin{tabular}{|c|c|c|c|c|}
\hline IL-10 (pg/ml) & & & & \\
\hline \multicolumn{5}{|l|}{ Intention-to-treat analysis } \\
\hline Baseline (63 vs. 59) & $9.43(8.85)$ & $9.09(12.56)$ & 0.34 (-3.59 to 4.26$)$ & 0.101 \\
\hline 12-week (43 vs. 42) & $8.05(9.13)$ & $5.74(8.10)$ & 2.31 ( -1.41 to 6.04$)$ & 0.016 \\
\hline 24-week (28 vs. 27) & $6.23(5.34)$ & $4.91(8.62)$ & $1.32(-2.59$ to 5.24$)$ & 0.012 \\
\hline \multicolumn{5}{|l|}{ Per-protocol analysis } \\
\hline Baseline (45 vs. 43) & $8.71(8.73)$ & $7.70(11.18)$ & $1.01(-3.23$ to 5.25$)$ & 0.209 \\
\hline 12-week (40 vs. 38) & $8.12(9.42)$ & $6.13(8.41)$ & $1.99(-2.05$ to 6.03$)$ & 0.038 \\
\hline 24-week (26 vs. 24) & $6.16(5.49)$ & 5.29 (9.09) & $0.87(-3.47$ to 5.22$)$ & 0.023 \\
\hline \multicolumn{5}{|l|}{ STRESS HORMONES } \\
\hline \multicolumn{5}{|l|}{ Cortisol (mg/L creatinine) } \\
\hline \multicolumn{5}{|l|}{ Intention-to-treat analysis } \\
\hline Baseline (62 vs. 62) & $35.50(19.56)$ & $32.70(17.45)$ & $2.80(-3.79$ to 9.39$)$ & 0.379 \\
\hline 12 weeks (46 vs. 42 ) & 31.15 (19.63) & $30.56(18.42)$ & 0.59 (-7.50 to 8.68$)$ & 0.937 \\
\hline 24 weeks (28 vs. 27) & $23.19(9.09)$ & $28.60(27.36)$ & $-5.41(-16.70$ to 5.88$)$ & 0.959 \\
\hline \multicolumn{5}{|l|}{ Per-protocol analysis } \\
\hline Baseline (43 vs. 46) & $35.90(20.62)$ & $31.43(17.07)$ & 4.47 ( -3.49 to 12.42$)$ & 0.293 \\
\hline 12 weeks (44 vs. 38 ) & $30.41(19.07)$ & $31.24(18.87)$ & $-0.83(-9.19$ to 7.54$)$ & 0.821 \\
\hline 24 weeks (26 vs. 23) & 23.99 ( 8.94$)$ & $30.66(29.16)$ & $-6.67(-19.68$ to 6.35$)$ & 0.986 \\
\hline \multicolumn{5}{|c|}{ Epinephrine (mg/L creatinine) } \\
\hline \multicolumn{5}{|l|}{ Intention-to-treat analysis } \\
\hline Baseline (62 vs. 63) & 12.22 (20.95) & $10.29(17.57)$ & $1.93(-4.89$ to 8.75$)$ & 0.576 \\
\hline 12 weeks (44 vs. 43 ) & $5.73(5.55)$ & $5.28(4.22)$ & $0.45(-1.65$ to 2.56$)$ & 0.779 \\
\hline 24 weeks (30 vs. 27) & $5.55(4.49)$ & $3.67(3.15)$ & $1.88(-0.20$ to 3.96$)$ & 0.067 \\
\hline \multicolumn{5}{|l|}{ Per-protocol analysis } \\
\hline Baseline (46 vs. 46) & $12.58(22.24)$ & $10.86(19.92)$ & $1.72(-7.03$ to 10.46$)$ & 0.87 \\
\hline 12 weeks (42 vs. 39) & $5.75(5.66)$ & $5.13(4.06)$ & $0.63(-1.55$ to 2.79$)$ & 0.273 \\
\hline 24 weeks (28 vs. 23) & $5.35(4.23)$ & $3.90(3.17)$ & $1.45(-0.69$ to 3.60$)$ & 0.098 \\
\hline \multicolumn{5}{|c|}{ Norepinephrine (mg/L creatinine) } \\
\hline \multicolumn{5}{|l|}{ Intention-to-treat analysis } \\
\hline Baseline (61 vs. 62) & $52.20(42.08)$ & $50.08(28.79)$ & $2.12(-10.79$ to 15.03$)$ & 0.85 \\
\hline 12 weeks (46 vs. 41 ) & $60.85(44.05)$ & $52.01(35.07)$ & 8.83 (-8.28 to 25.95$)$ & 0.748 \\
\hline 24 weeks (30 vs. 27) & $52.04(35.50)$ & $43.87(34.52)$ & $8.17(-10.46$ to 26.80$)$ & 0.198 \\
\hline \multicolumn{5}{|l|}{ Per-protocol analysis } \\
\hline Baseline (44 vs. 45) & 56.44 (47.59) & 53.29 (31.47) & 3.15 (-13.93 to 20.23$)$ & 0.715 \\
\hline 12 weeks (44 vs. 37 ) & $61.49(44.64)$ & $51.31(32.35)$ & 10.18 (-7.36 to 27.73$)$ & 0.76 \\
\hline 24 weeks (28 vs. 23) & $53.93(35.94)$ & $45.11(35.42)$ & 8.81 (-11.38 to 29.01$)$ & 0.197 \\
\hline
\end{tabular}

CCBT = Conventional cognitive-behavioral therapy; RCBT = religious CBT; SD = standard deviation, CI = confidence intervals; CRP = C-reactive protein (acute phase protein), TNF- $\alpha=$ tumor necrosis factor- $\alpha$, IL = interleukin, IFN = interferon. ${ }^{1}$ Means and SD (standard deviations) are for original data (not log transformed); ${ }^{2}$ p values are for analyses using log transformed data, except for IL-4 and IL-12; ${ }^{3} \mathrm{~N}$ (sample size) for CCBT vs. RCBT; mean values, SD, and mean differences are for raw data. 
Table 3. Effect of RCBT vs. CCBT on trajectory of change in inflammatory biomarkers and stress hormones from baseline to 24 weeks.

B

\section{SE}

t value

p

\section{PRO-INFLAMMATORY}

\section{$\log$ CRP (mg/L)}

Intent-to-treat (ITT) analysis

Time
Main effect of group
Group $\times$ time interaction
Per-protocol $(P P)$ analysis
Time
Main effect of group
Group $\times$ time interaction
Log TNF- $\boldsymbol{\alpha}$ (pg/ml)
Intent-to-treat analysis
Time
Main effect of group
Group $\times$ time interaction
Per-protocol analysis
Time

\section{$\log$ IL-1 $\beta$ (pg/ml)}

Intent-to-treat analysis

$$
\text { Time }
$$

Main effect of group

Group $\times$ time interaction

Per-protocol analysis

$$
\text { Time }
$$

Main effect of group

Group $\times$ time interaction

$\log$ IFN- $\gamma(\mathrm{pg} / \mathrm{ml})$

Intent-to-treat analysis

$$
\text { Time }
$$

Main effect of group

Group $\times$ time interaction

Per-protocol analysis

$$
\text { Time }
$$

Main effect of group

Group $\times$ time interaction

$$
0.07
$$

0.10

$-0.07$

0.09

0.13

$-0.09$

$-0.01$

0.01

0.00

0.00

0.05

$-0.01$

$-0.03$

0.04

0.04

$-0.03$

0.03

0.03

$-0.02$

0.05

0.02

$-0.02$

0.02

0.02
0.04

0.01

$-1.40$

0.30

0.04

$-0.02$

0.98

$-0.41$

1.18

0.242

0.60

$0.15 \quad 0.87$

0.163

0.767

0.681

0.549

0.385

0.135

0.071

0.441

0.242

0.044 


\section{Continued}

\begin{tabular}{|c|c|c|c|c|}
\hline Log IL-6 (pg/ml) & & & & \\
\hline \multicolumn{5}{|l|}{ Intent-to-treat analysis } \\
\hline Time & 0.01 & 0.04 & 0.13 & 0.897 \\
\hline Main effect of group & 0.04 & 0.12 & 0.34 & 0.738 \\
\hline Group $\times$ time interaction & -0.03 & 0.06 & -0.46 & 0.645 \\
\hline \multicolumn{5}{|l|}{ Per-protocol analysis } \\
\hline Time & 0.03 & 0.04 & 0.62 & 0.533 \\
\hline Main effect of group & 0.00 & 0.15 & -0.01 & 0.990 \\
\hline Group $\times$ time interaction & -0.02 & 0.06 & -0.36 & 0.716 \\
\hline \multicolumn{5}{|l|}{ IL-12 p70 (pg/ml) } \\
\hline \multicolumn{5}{|l|}{ Intent-to-treat analysis } \\
\hline Time & -0.18 & 0.08 & -2.16 & 0.033 \\
\hline Main effect of group & -0.09 & 0.57 & -0.17 & 0.869 \\
\hline Group $\times$ time interaction & 0.06 & 0.12 & 0.52 & 0.602 \\
\hline \multicolumn{5}{|l|}{ Per-protocol analysis } \\
\hline Time & -0.17 & 0.09 & -1.90 & 0.059 \\
\hline Main effect of group & -0.13 & 0.46 & -0.29 & 0.774 \\
\hline Group $\times$ time interaction & 0.07 & 0.12 & 0.55 & 0.587 \\
\hline \multicolumn{5}{|l|}{ ANTI-INFLAMMATORY } \\
\hline \multicolumn{5}{|l|}{ Log IL-1ra (pg/ml) } \\
\hline \multicolumn{5}{|l|}{ Intent-to-treat analysis } \\
\hline Time & -0.04 & 0.05 & -0.78 & 0.436 \\
\hline Main effect of group & 0.06 & 0.19 & 0.33 & 0.741 \\
\hline Group $\times$ time interaction & 0.05 & 0.07 & 0.78 & 0.436 \\
\hline \multicolumn{5}{|l|}{ Per-protocol analysis } \\
\hline Time & -0.05 & 0.06 & -0.89 & 0.377 \\
\hline Main effect of group & -0.02 & 0.23 & -0.08 & 0.935 \\
\hline Group $\times$ time interaction & 0.07 & 0.08 & 0.91 & 0.364 \\
\hline \multicolumn{5}{|l|}{ IL-4 (pg/ml) } \\
\hline \multicolumn{5}{|l|}{ Intent-to-treat analysis } \\
\hline Time & -2.31 & 0.71 & -3.28 & 0.001 \\
\hline Main effect of group & -0.18 & 2.53 & -0.07 & 0.945 \\
\hline Group $\times$ time interaction & 0.49 & 0.99 & 0.49 & 0.625 \\
\hline \multicolumn{5}{|l|}{ Per-protocol analysis } \\
\hline Time & -1.45 & 0.64 & -2.27 & 0.025 \\
\hline Main effect of group & -0.03 & 2.62 & -0.01 & 0.99 \\
\hline Group $\times$ time interaction & -0.32 & 0.89 & -0.36 & 0.719 \\
\hline
\end{tabular}




\section{Continued}

\begin{tabular}{|c|c|c|c|c|}
\hline \multicolumn{5}{|l|}{$\log$ IL-10 (pg/ml) } \\
\hline \multicolumn{5}{|l|}{ Intent-to-treat analysis } \\
\hline Time & -0.12 & 0.04 & -2.87 & 0.005 \\
\hline Main effect of group & 0.11 & 0.16 & 0.66 & 0.514 \\
\hline Group $\times$ time interaction & 0.13 & 0.06 & 2.11 & 0.037 \\
\hline \multicolumn{5}{|l|}{ Per-protocol analysis } \\
\hline Time & -0.11 & 0.05 & -2.33 & 0.021 \\
\hline Main effect of group & 0.09 & 0.19 & 0.47 & 0.642 \\
\hline Group $\times$ time interaction & 0.12 & 0.06 & 1.93 & 0.056 \\
\hline \multicolumn{5}{|l|}{ STRESS HORMONES } \\
\hline \multicolumn{5}{|l|}{ Log Cortisol (mg/L creatinine) } \\
\hline \multicolumn{5}{|l|}{ Intent-to-treat analysis } \\
\hline Time & -0.03 & 0.02 & -1.34 & 0.181 \\
\hline Main effect of group & 0.08 & 0.07 & 1.18 & 0.241 \\
\hline Group $\times$ time interaction & -0.04 & 0.03 & -1.17 & 0.245 \\
\hline \multicolumn{5}{|l|}{ Per-protocol analysis } \\
\hline Time & -0.01 & 0.03 & -0.53 & 0.598 \\
\hline Main effect of group & 0.11 & 0.08 & 1.36 & 0.175 \\
\hline Group $\times$ time interaction & -0.05 & 0.04 & -1.38 & 0.170 \\
\hline \multicolumn{5}{|c|}{ Log Epinephrine (mg/L creatinine) } \\
\hline \multicolumn{5}{|l|}{ Intent-to-treat analysis } \\
\hline Time & -0.24 & 0.05 & -4.86 & $<0.0001$ \\
\hline Main effect of group & -0.19 & 0.13 & -1.43 & 0.156 \\
\hline Group $\times$ time interaction & 0.13 & 0.07 & 1.88 & 0.063 \\
\hline \multicolumn{5}{|l|}{ Per-protocol analysis } \\
\hline Time & -0.25 & 0.05 & -4.51 & $<0.0001$ \\
\hline Main effect of group & -0.15 & 0.15 & -0.98 & 0.328 \\
\hline Group $\times$ time interaction & 0.11 & 0.08 & 1.52 & 0.130 \\
\hline \multicolumn{5}{|c|}{ Log Norepinephrine (mg/L creatinine) } \\
\hline \multicolumn{5}{|l|}{ Intent-to-treat analysis } \\
\hline Time & -0.04 & 0.03 & -1.29 & 0.200 \\
\hline Main effect of group & -0.06 & 0.08 & -0.76 & 0.447 \\
\hline Group $\times$ time interaction & 0.05 & 0.04 & 1.15 & 0.253 \\
\hline \multicolumn{5}{|l|}{ Per-protocol analysis } \\
\hline Time & -0.04 & 0.03 & -1.34 & 0.184 \\
\hline Main effect of group & -0.07 & 0.09 & -0.78 & 0.438 \\
\hline Group $\times$ time interaction & 0.05 & 0.04 & 1.04 & 0.301 \\
\hline
\end{tabular}

RCBT = religious CBT; CCBT $=$ Conventional cognitive-behavioral therapy; CRP $=$ C-reactive protein (acute phase protein), TNF- $\alpha=$ tumor necrosis factor- $\alpha$, $\mathrm{IL}=$ interleukin, IFN = interferon. B = unstandardized coefficient for "time” indicates change in biomarker during the course of therapy (independent of group); the "main effect of group" represents the average difference between treatment groups (RCBT $=1$, CCBT $=0$ ); and for the "group $\times$ time interaction" indicates whether the two groups changed at the same rate; B's are from mixed effects growth curve models; $\mathrm{SE}=$ standard error; $\mathrm{p}=$ significance level; $\mathrm{N}=121$ - $127 \mathrm{for}$ ITT analyses and 88 - 92 for PP analyses; log-transformed data used, except for IL-4 and IL-12. 
only those who received at least 5 of the 10 treatment sessions (to determine changes in biomarkers in those who received at least half of the treatment).

To examine the differential effect that baseline religiosity had on the effectiveness of RCBT vs. CCBT, we entered the summed measure of baseline religiosity and its interaction with treatment group into the mixed models above (Table 4). If the interaction was statistically significant or nearly so ( $<<0.10)$, we dichotomized the summed religiosity variable at the mid-point into low and high religiosity categories and repeated the analysis (group, time, group by time interaction) in each category. To examine the effect of baseline religiosity on the trajectory of change in biomarkers regardless of treatment group, we entered baseline religiosity into the mixed model, along with group, time, and group by time interaction (Table 5). Statistical analyses were performed using SAS (version 9.3; SAS Institute Inc., Cary, North Carolina). The significance level was set at $\mathrm{p}=0.05$ for all endpoints without correction for multiple comparisons given the exploratory nature of these analyses.

\section{Results}

As reported in the parent study [41], a total of 450 potential participants were screened between June 2011 and June 2013, of whom 187 were assessed by in-person screening and 132 were randomized to treatment group. Three clients who did not fulfill inclusion/exclusion criteria were mistakenly randomized in the trial, but were included to keep randomization intact. The characteristics of the sample are described in Table 1. Participants scored an average of $25.3 \pm 8.5$ on the BDI, which indicates moderate depression severity (but well above the cutoff of 10 for depression on the scale). There were no significant differences between treatment groups on any of the characteristics in Table 1. As reported elsewhere, mean level of depressive symptoms in both groups decreased progressively during the course of treatment (from $25.3 \pm 8.5$ at baseline to $11.8 \pm 9.4$ at 12-week and $11.8 \pm 11.2$ at 24-week), with no difference between RCBT and CCBT [41]. Median levels of baseline CRP, pro-inflammatory cytokines, and stress hormones tended to be higher in this sample compared to those in a community sample of non-depressed persons enrolled in the Midlife in the United States Study (MIDUS) [34].

Based on the existing research suggesting a relationship between stress biomarkers and depression, we expected that a change (i.e., decrease) in depression severity during the course of treatment would be correlated with a decrease in pro-inflammatory biomarkers, an increase in anti-inflammatory cytokines, and a reduction in urinary stress hormones. However, decrease in severity of depressive symptoms was not significantly correlated with changes in pro-inflammatory proteins or cytokines (CRP, $r=-0.03, \mathrm{p}=0.810$; TNF- $\alpha, \mathrm{r}=-0.03, \mathrm{p}=0.745$; IL-1 $\beta, \mathrm{R}=0.02, \mathrm{p}=0.887$; IFN- $\gamma, \mathrm{r}=0.08, \mathrm{p}=0.440$; IL-6, $\mathrm{r}=0.07, \mathrm{p}=0.507$; IL-12, $\mathrm{r}=-0.05, \mathrm{p}=0.675$ ), changes in anti-inflammatory cytokines (IL-1ra, $r=-0.00, p=0.984$; IL-4, $r=-0.00$, $p=0.984$; IL-10, $r=0.04$, $p=0.736$ ), or changes in urinary stress hormones (cortisol, $r=0.08, p=0.469$; epinephrine, $r=-0.01, p=0.953$; norepinephrine, $r=-0.05, p=0.651$ ). This is despite the fact that depressive symptoms decreased in the overall trial population by an average of 13.9 points on the BDI-II, with changes ranging from a decrease of 38 points to an increase of 29 points. Similarly, there was a wide range of change in biomarkers during the study.

\subsection{Effect of RCBT vs. CCBT on Biomarkers}

In the ITT analysis that addressed our primary hypothesis, no difference was found between RCBT and CCBT in their effects on stress biomarkers in any comparison at baseline, 12 weeks, or 24 weeks, except for the antiinflammatory cytokine IL-10, where a greater reduction was seen with RCBT at both 12 and 24 weeks (Table 2, Figure 1). The PP analysis among clients who had received at least 5 of the 10 treatment sessions also indicated no differences except for IL-10, supporting the findings from the ITT analysis.

Several pro-inflammatory, anti-inflammatory, and stress hormone indicators changed significantly over time in the mixed effects growth curve models (in both expected and unexpected directions) (Table 3). The ITT analysis indicated that the stress hormone epinephrine decreased significantly over time in the expected direction (time $\mathrm{B}=-0.24$, SE [standard error] $=0.05, \mathrm{t}=-4.86, \mathrm{p}<0.0001$ ) (Figure 2). However, contrary to expectations the anti-inflammatory cytokines IL-4 and IL-10 also decreased over time (IL-4 time B $=-2.31$, SE = $0.71, \mathrm{t}=-3.28, \mathrm{p}=0.001 ; \mathrm{IL}-10$ time $\mathrm{B}=-0.12, \mathrm{SE}=0.04, \mathrm{t}=-2.87, \mathrm{p}=0.005$ ). Also, pro-inflammatory acute phase protein CRP increased over time, an effect which in the PP analysis became significant (time $\mathrm{B}=0.09$, $\mathrm{SE}$ $=0.04, \mathrm{t}=2.03, \mathrm{p}=0.044)$ (Figure 3).

However, there was no significant difference in average treatment effects (i.e., main effect of group) between RCBT and CCBT on any biomarker, including IL-10, in either ITT or PP analyses. 
Table 4. Interaction between baseline religiosity and treatment group on trajectory of change in inflammatory markers and stress hormones.

\begin{tabular}{|c|c|c|c|c|}
\hline & B & SE & t value & $\mathbf{p}$ \\
\hline \multicolumn{5}{|l|}{ PRO-INFLAMMATORY } \\
\hline \multicolumn{5}{|l|}{$\log$ CRP (mg/L) } \\
\hline Intent-to-treat analysis (ITT) & 0.00 & 0.00 & -0.19 & 0.853 \\
\hline Per-protocol analysis (PP) & 0.00 & 0.00 & -0.28 & 0.779 \\
\hline \multicolumn{5}{|l|}{$\log$ TNF- $\alpha(p g / m l)$} \\
\hline ITT & 0.00 & 0.00 & -0.30 & 0.763 \\
\hline PP & 0.00 & 0.00 & -0.41 & 0.683 \\
\hline \multicolumn{5}{|l|}{$\log$ IL-1 $\beta(p g / m l)$} \\
\hline ITT & 0.00 & 0.00 & -0.92 & 0.360 \\
\hline $\mathrm{PP}$ & -0.01 & -0.01 & -1.08 & 0.282 \\
\hline \multicolumn{5}{|l|}{$\log$ IFN- $\gamma(\mathbf{p g} / \mathrm{ml})$} \\
\hline ITT & 0.00 & 0.00 & -0.49 & 0.628 \\
\hline PP & 0.00 & 0.00 & -0.71 & 0.478 \\
\hline \multicolumn{5}{|l|}{$\log$ IL-6 (pg/ml) } \\
\hline ITT & -0.01 & 0.00 & -1.98 & 0.050 \\
\hline PP & -0.01 & 0.00 & -2.66 & 0.009 \\
\hline \multicolumn{5}{|l|}{ IL-12 p70 (pg/ml) } \\
\hline ITT & -0.02 & 0.02 & -0.95 & 0.345 \\
\hline PP & -0.01 & 0.02 & -0.36 & 0.721 \\
\hline \multicolumn{5}{|l|}{ ANTI-INFLAMMATORY } \\
\hline \multicolumn{5}{|l|}{ Log IL-1ra (pg/ml) } \\
\hline ITT & -0.01 & 0.01 & -1.94 & 0.055 \\
\hline $\mathrm{PP}$ & -0.02 & 0.01 & -2.14 & 0.034 \\
\hline \multicolumn{5}{|l|}{ IL-4 (pg/ml) } \\
\hline ITT & -0.12 & 0.08 & -1.57 & 0.118 \\
\hline $\mathrm{PP}$ & -0.12 & 0.08 & -1.45 & 0.149 \\
\hline \multicolumn{5}{|l|}{$\log 1 \mathrm{~L}-10(\mathrm{pg} / \mathrm{ml})$} \\
\hline ITT & -0.01 & 0.01 & -1.54 & 0.126 \\
\hline $\mathrm{PP}$ & -0.01 & 0.01 & -1.21 & 0.228 \\
\hline \multicolumn{5}{|l|}{ STRESS HORMONES } \\
\hline \multicolumn{5}{|l|}{ Log Cortisol (mg/L creatinine) } \\
\hline ITT & 0.00 & 0.00 & -1.45 & 0.148 \\
\hline PP & 0.00 & 0.00 & -1.15 & 0.250 \\
\hline \multicolumn{5}{|c|}{ Log Epinephrine (mg/L creatinine) } \\
\hline ITT & 0.00 & 0.00 & -0.70 & 0.486 \\
\hline $\mathrm{PP}$ & 0.00 & 0.00 & 0.29 & 0.776 \\
\hline \multicolumn{5}{|c|}{ Log Norepinephrine (mg/L creatinine) } \\
\hline ITT & 0.00 & 0.00 & -0.05 & 0.963 \\
\hline PP & 0.00 & 0.00 & 0.41 & 0.682 \\
\hline
\end{tabular}

CRP = C-reactive protein, TNF- $\alpha=$ tumor necrosis factor- $\alpha$, IL = interleukin, IFN = interferon; $\mathrm{B}=$ unstandardized coefficient for the religiosity by group interaction term in the mixed effects growth curve model; $\mathrm{SE}=$ standard error; $\mathrm{p}=$ significance level; $\mathrm{N}=121-127$ for ITT analyses and 88 92 for PP analyses; log transformed data used, except for IL-4 and IL-12. 
Table 5. Effect of baseline religiosity on trajectory of change in inflammatory markers and stress hormones independent of treatment group.

\begin{tabular}{|c|c|c|c|c|}
\hline & $\mathbf{B}$ & SE & t value & $\mathbf{p}$ \\
\hline \multicolumn{5}{|l|}{ PRO-INFLAMMATORY } \\
\hline \multicolumn{5}{|l|}{$\log$ CRP (mg/L) } \\
\hline Intent-to-treat analysis (ITT) & 0.001 & 0.002 & 0.66 & 0.511 \\
\hline Per-protocol analysis (PP) & 0.001 & 0.002 & 0.47 & 0.642 \\
\hline \multicolumn{5}{|l|}{$\log$ TNF- $\alpha(\mathrm{pg} / \mathrm{ml})$} \\
\hline ITT & 0.000 & 0.001 & 0.18 & 0.857 \\
\hline PP & 0.000 & 0.001 & 0.78 & 0.438 \\
\hline \multicolumn{5}{|l|}{$\log$ IL-1 $\beta$ (pg/ml) } \\
\hline ITT & 0.001 & 0.002 & 0.59 & 0.556 \\
\hline PP & 0.001 & 0.003 & 0.37 & 0.713 \\
\hline \multicolumn{5}{|l|}{$\log$ IFN- $\gamma(\mathrm{pg} / \mathrm{ml})$} \\
\hline ITT & 0.004 & 0.002 & 2.42 & 0.017 \\
\hline PP & 0.005 & 0.002 & 2.28 & 0.024 \\
\hline \multicolumn{5}{|l|}{ Log IL-6 (pg/ml) } \\
\hline ITT & 0.001 & 0.002 & 0.35 & 0.725 \\
\hline PP & 0.000 & 0.002 & 0.23 & 0.820 \\
\hline \multicolumn{5}{|l|}{ IL-12 p70 (pg/ml) } \\
\hline ITT & 0.021 & 0.011 & 1.96 & 0.052 \\
\hline PP & 0.007 & 0.008 & 0.90 & 0.369 \\
\hline \multicolumn{5}{|l|}{ ANTI-INFLAMMATORY } \\
\hline \multicolumn{5}{|l|}{ Log IL-1ra (pg/ml) } \\
\hline ITT & 0.003 & 0.003 & 1.15 & 0.252 \\
\hline PP & 0.002 & 0.004 & 0.62 & 0.539 \\
\hline \multicolumn{5}{|l|}{ IL-4 (pg/ml) } \\
\hline ITT & 0.027 & 0.040 & 0.67 & 0.502 \\
\hline PP & 0.017 & 0.042 & 0.39 & 0.694 \\
\hline \multicolumn{5}{|l|}{$\log$ IL-10 (pg/ml) } \\
\hline ITT & 0.001 & 0.003 & 0.54 & 0.593 \\
\hline PP & 0.000 & 0.003 & -0.13 & 0.899 \\
\hline \multicolumn{5}{|l|}{ STRESS HORMONES } \\
\hline \multicolumn{5}{|l|}{ Log Cortisol (mg/L creatinine) } \\
\hline ITT & 0.001 & 0.001 & 1.83 & 0.069 \\
\hline $\mathrm{PP}$ & 0.002 & 0.001 & 1.77 & 0.079 \\
\hline \multicolumn{5}{|c|}{ Log Epinephrine (mg/L creatinine) } \\
\hline ITT & 0.000 & 0.001 & 0.24 & 0.808 \\
\hline $\mathrm{PP}$ & 0.001 & 0.000 & 0.69 & 0.490 \\
\hline \multicolumn{5}{|c|}{ Log Norepinephrine (mg/L creatinine) } \\
\hline ITT & 0.000 & 0.001 & 0.15 & 0.880 \\
\hline PP & 0.000 & 0.001 & -0.11 & 0.914 \\
\hline
\end{tabular}

CRP = C-reactive protein, TNF- $\alpha=$ tumor necrosis factor- $\alpha$, IL = interleukin, IFN = interferon; B = unstandardized coefficient for the baseline religiosity term in the mixed effects growth curve model; $\mathrm{SE}=$ standard error; $\mathrm{p}=$ significance level; $\mathrm{N}=121$ - 127 for ITT and 88 - 92 for PP analyses; log transformed data used in analyses, except for IL-4 and IL-12. 


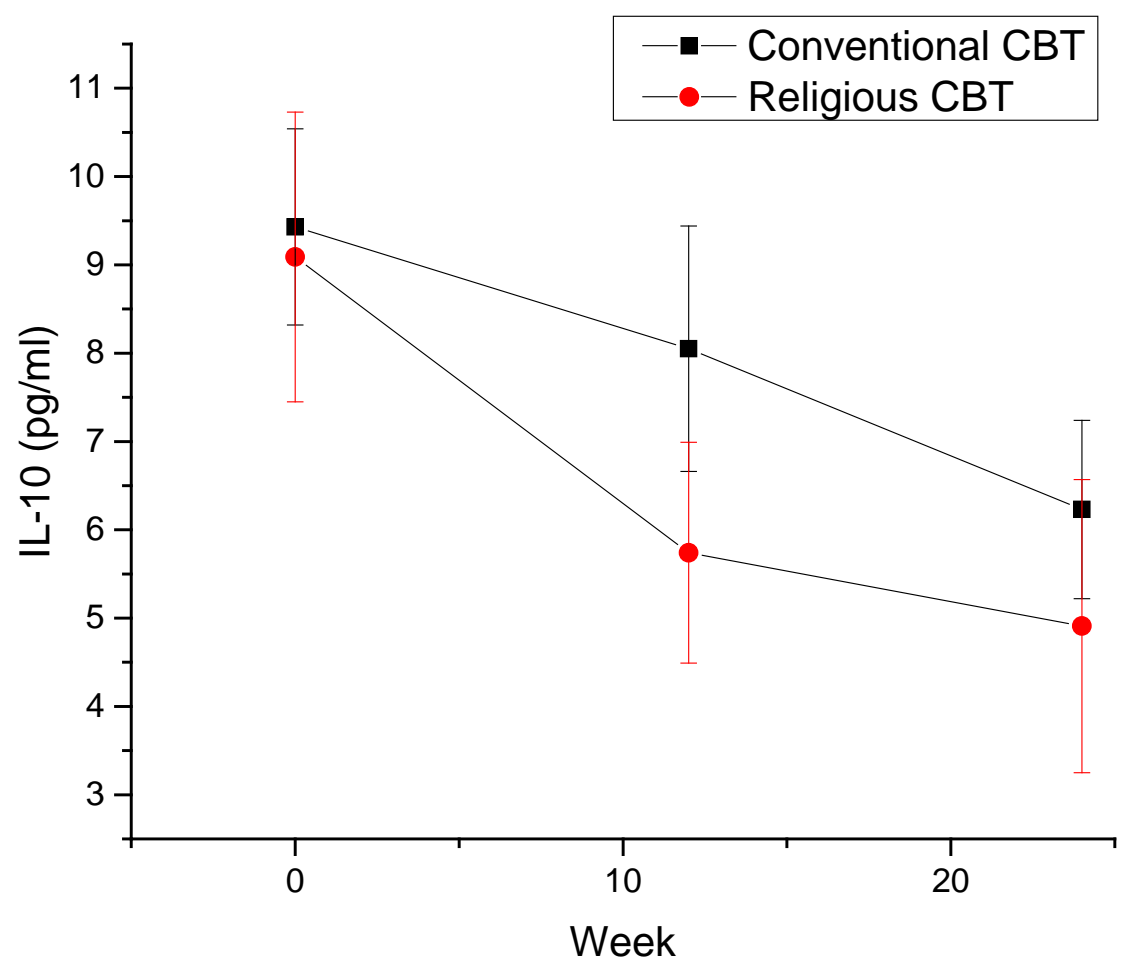

Figure 1. Effects of RCBT vs. CCBT on average level of anti-inflammatory cytokine interleukin 10 (IL-10) ( \pm standard error). Mixed model intent-to-treat analysis (log transformed): time $B=-0.12, p=0.005$; main effect of group $B=0.11$ (where RCBT $=1$ ), $\mathrm{p}=0.514$; group $\times$ time interaction $\mathrm{B}=0.13, \mathrm{p}=0.037$.

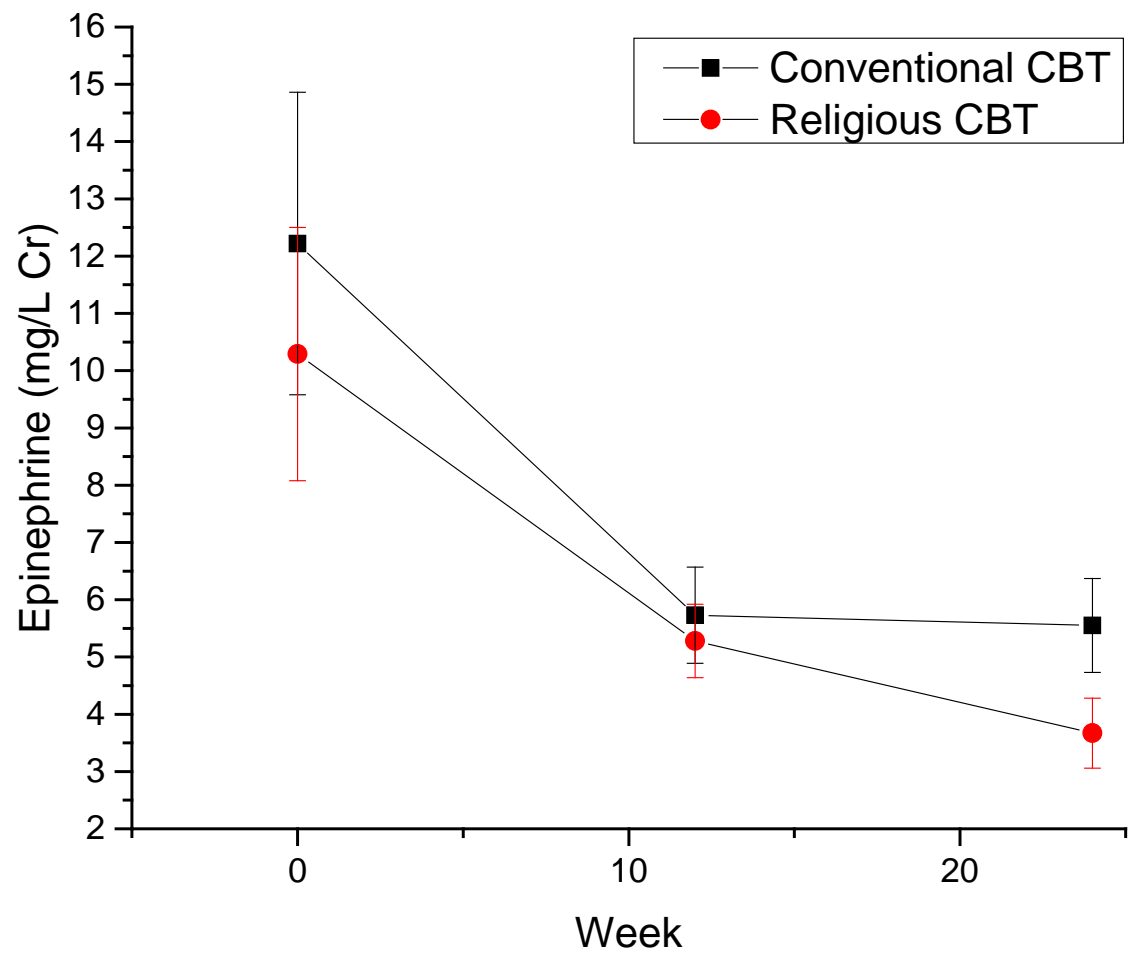

Figure 2. Effects of RCBT vs. CCBT on average level of urine epinephrine ( \pm standard error). Mixed model intent-to-treat analysis (log transformed): time $B=-0.24, p<0.0001$; main effect of group $B=-0.19, p=0.156$; group $\times$ time interaction $\mathrm{B}=0.13, \mathrm{p}=0.063$. 


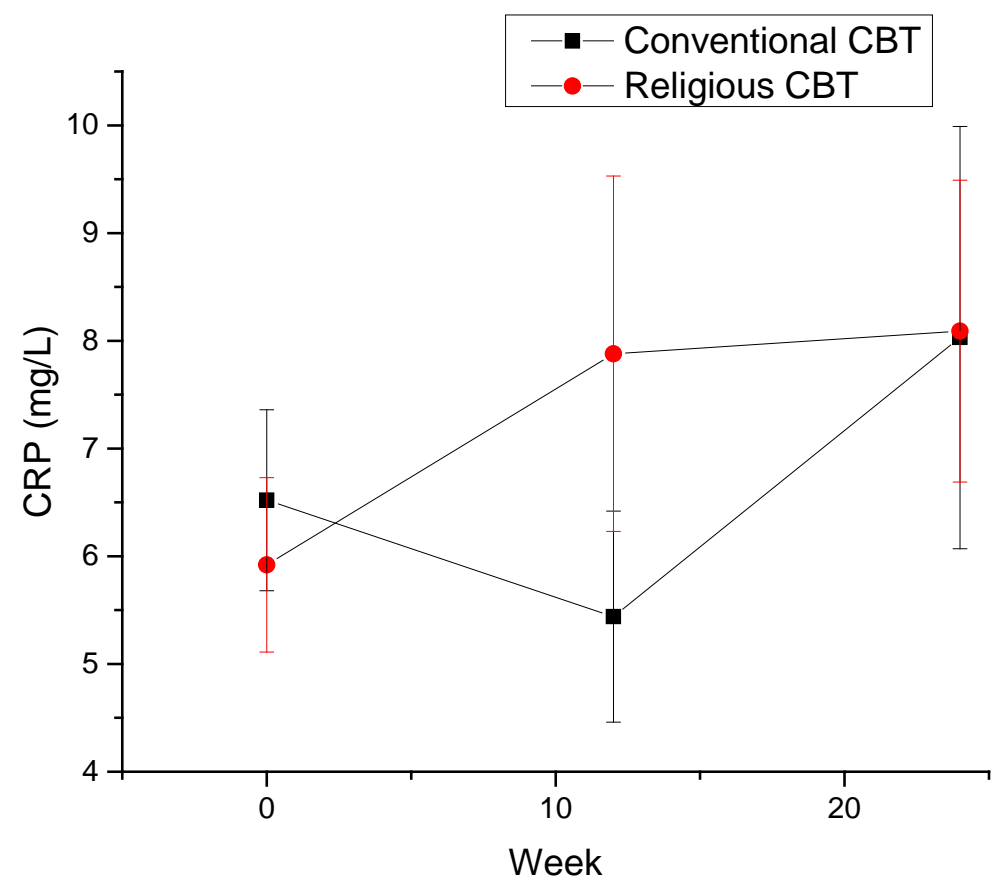

Figure 3. Effects of RCBT vs. CCBT on average level of C-reactive protein (CRP) ( \pm standard error). Mixed model intent-to-treat analysis ( $\log$ transformed): time $\mathrm{B}=0.07, \mathrm{p}=0.071$; main effect of group $\mathrm{B}=0.10, \mathrm{p}=0.441$; group $\times$ time interaction $\mathrm{B}=-0.07, \mathrm{p}=0.242$.

\subsection{Differential Effects of Religiosity}

With regard to the impact of RCBT vs. CCBT in those with higher and low religiosity scores, no significant effect was seen on any pro-inflammatory, anti-inflammatory, or stress hormone outcome examined in the ITT analysis, except for IL6 (Table 4). For IL-6, the interaction between overall religiosity and treatment group in the mixed effect growth curve model was significant in both ITT and PP analyses $(\mathrm{B}=-0.007, \mathrm{SE}=0.003, \mathrm{t}=$ $-1.98, \mathrm{p}=0.050$, and $\mathrm{B}=-0.011, \mathrm{SE}=0.004, \mathrm{t}=-2.66, \mathrm{p}=0.009$, respectively). The ITT analysis in the low religiosity group indicated that CCBT was more effective than RCBT in lowering IL-6 levels (main effect $\mathrm{B}=$ $0.38, \mathrm{SE}=0.15, \mathrm{t}=2.52, \mathrm{p}=0.014, \mathrm{n}=62$ ); this was replicated in the PP analysis (main effect $\mathrm{B}=0.48, \mathrm{SE}=$ $0.18, \mathrm{t}=2.62, \mathrm{p}=0.011, \mathrm{n}=44$ ). In those with high religiosity, RCBT was no more effective than CCBT in the ITT analysis (main effect $\mathrm{B}=-0.28, \mathrm{SE}=0.19, \mathrm{t}=-1.44, \mathrm{p}=0.155, \mathrm{n}=64$ ), but was more effective in the PP analysis (main effect $\mathrm{B}=-0.47, \mathrm{SE}=0.24, \mathrm{t}=2.00, \mathrm{p}=0.050, \mathrm{n}=45$ ) (Figure 4).

\subsection{Effect of Baseline Religiosity on Biomarkers}

When overall religiosity was entered into the mixed effects growth curve models, effects were observed on changes in several biomarkers over time independent of treatment group (Table 5). The effects, however, were not as hypothesized. Results from the ITT analysis indicated that greater religiosity at baseline predicted an increase in pro-inflammatory cytokines IFN $-\gamma(\mathrm{B}=0.004, \mathrm{SE}=0.002, \mathrm{t}=2.42, \mathrm{p}=0.017)$ and IL-12-p70 $(\mathrm{B}=$ $0.021, \mathrm{SE}=0.011, \mathrm{t}=1.96, \mathrm{p}=0.052)$, and tended to predict an increase in urinary cortisol $(\mathrm{B}=0.001, \mathrm{SE}=$ $0.001, \mathrm{t}=1.83, \mathrm{p}=0.069$ ). Religiosity had no significant effect on any other biomarker.

\section{Discussion}

To our knowledge, this is the first study to compare the effects of religiously-integrated CBT compared to conventional CBT on changes in a wide range of pro-inflammatory, anti-inflammatory, and stress hormone biomarkers in persons with major depressive disorder and chronic medical illness who were at least somewhat religious or spiritual. Despite the finding that a number of these biomarkers changed during the course of therapy, neither RCBT nor CCBT were effective in reducing pro-inflammatory cytokines. The only exception in this re- 

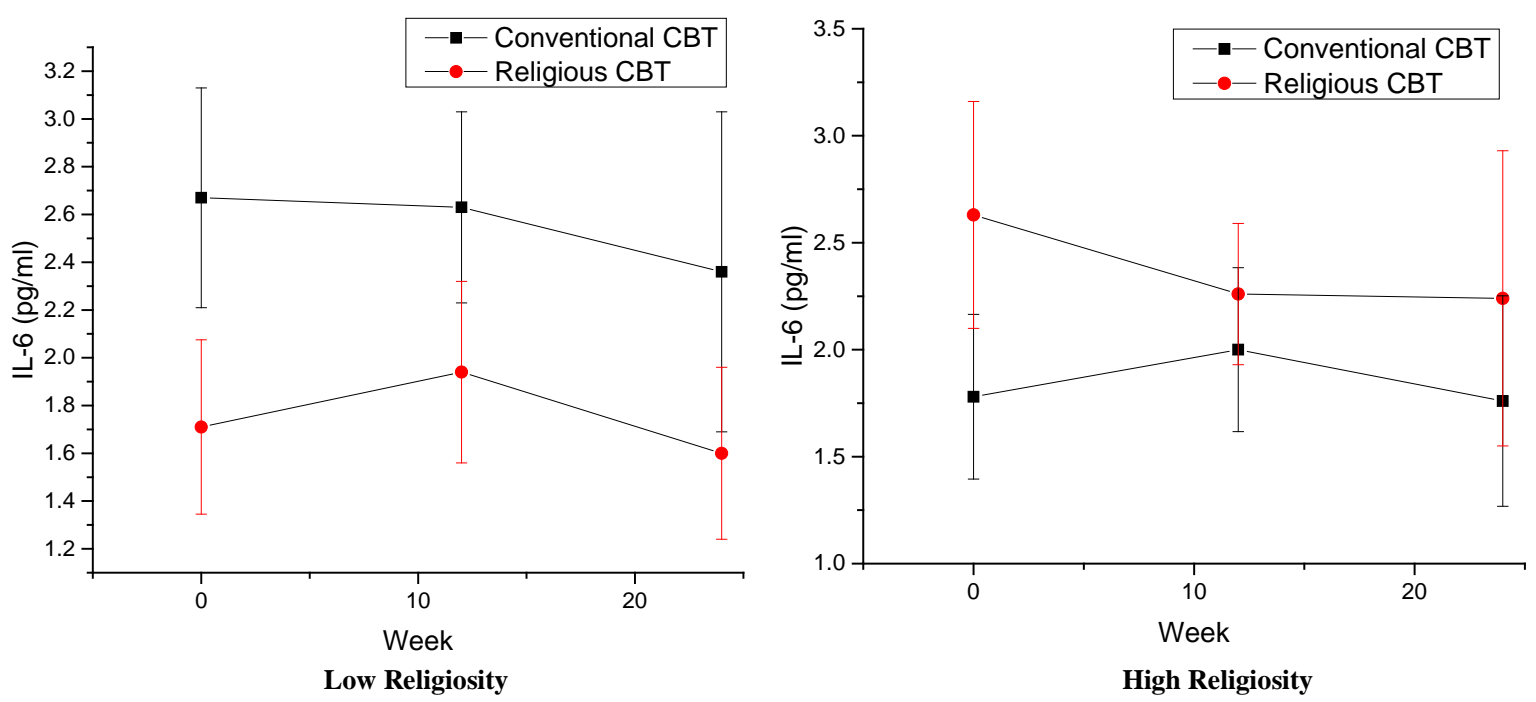

Figure 4. Effects of RCBT vs. CCBT on the average level (original values) of pro-inflammatory cytokine interleukin-6 (IL-6) ( \pm standard error) in those with low and high religiosity. Low religiosity: mixed model per-protocol analysis (log transformed): time $\mathrm{B}=0.09, \mathrm{p}=0.084$; main effect of group $\mathrm{B}=0.48, \mathrm{p}=0.011$; group $\times$ time interaction $\mathrm{B}=-0.13$, $\mathrm{p}=$ 0.063 ( $n=44)$; high religiosity: mixed model per-protocol analysis (log transformed): time $B=-0.03, p=0.719$; main effect of group $B=-0.47, p=0.050$; group $\times$ time interaction $B=0.08, p=0.446(n=45)$.

gard emerged from the moderator analysis. In the low religiosity group, CCBT was significantly more effective in reducing the pro-inflammatory cytokine IL-6, whereas in the high religiosity group, RCBT was more effective in reducing IL-6 in the per protocol analysis. Baseline religiosity, however, predicted an increase in pro-inflammatory cytokines IFN- $\gamma$ and IL-12-p70 and tended to do likewise with urinary cortisol (which is usually associated with greater depression [54] [55]).

\subsection{Interpretation}

The only findings in this study that supported our hypotheses were the reduction in urinary epinephrine over time as MDD was treated and the interaction of religiosity with treatment type for the marker IL-6. The former is consistent with prior research indicating higher levels of stress hormones in those with MDD and a decline in those hormones in response to treatment [56]. The latter is consistent with our original report that CCBT tended to be more effective than RCBT in the treatment of MDD in those who were less religious, whereas RCBT tended to be more effective in those who were more religious [41].

Why, however, was RCBT in general not more effective than CCBT in reducing pro-inflammatory cytokines, increasing anti-inflammatory cytokines, and reducing stress hormones, biomarkers known to be associated with MDD? One finding that may have influenced these results was that change in depressive symptoms was not associated with change in any of the inflammatory markers or stress hormones measured here, despite a sharp mean drop in BDI-II scores over the time of the trial. Had there not been such a decrease in symptoms, we might have attributed the failure to detect differences in treatment effect to the mild to moderate level of depression at baseline (ranging from 10 to 42). This lack of an association between change in depression with treatment and change in biomarkers remains an unexplained finding. If changes in biomarker levels during the study were not related to changes in depression, then the treatments for depression examined here may not have had much of an effect on changes in biomarkers either. Several biomarkers (four of twelve) did change during the study, although the change was in expected (one) and unexpected directions (three). There was no way, however, to determine whether those changes were due to a treatment effect, regression to the mean, or a chance finding, given the inconsistent pattern of change and lack of a no-treatment control group.

Failure to find a difference in biomarker change between RCBT and CCBT may also have been due to the similarity of the interventions. Both therapies addressed dysfunctional cognitions and behaviors and did so in broadly spiritual ways (focusing on meaning and purpose, forgiveness, gratitude, altruism, social connections, etc.), with the only difference being the religious nature of motivations for change. Given that studies comparing 
two types of psychotherapy often do not report significant differences [57], and given the many similarities in the two treatment approaches examined here, perhaps failure to find a difference in clinical or physiological outcomes is not too surprising.

The positive correlation between baseline religiosity and an increase in pro-inflammatory markers was also a curious and unexpected finding given prior research. Could religious people have become more physiologically stressed by the treatment even though their depressive symptoms lessened? Might the religious element of RCBT have stressed certain individuals with its reference to religious issues, even though the CBT elements helped? Neither of these explanations are likely since the effect was present in both RCBT and CCBT groups (i.e., was independent of treatment group). A "healthy" physiological response may also differ depending on the condition. The goal of treatment is to produce an optimal balance in pro- and anti-inflammatory responses, and this could involve an increase in certain inflammatory biomarkers such as IFN- $\gamma$ that can actually decrease in response to stress [58].

\subsection{Limitations}

A number of limitations in the present study may have influenced our findings. First, our sample consisted of persons with chronic medical illnesses who were taking a wide range of medications that could influence levels of inflammatory markers and stress hormones. Although we did our best to exclude individuals with obvious inflammatory disorders and those taking drugs that suppress the immune system or affect endocrine functions, individuals with conditions or on medication that could have affected the results of biomarker analyses may have ended up in the sample. This likely added to the variance in our outcomes, making it difficult to identify differences between treatments or associations with depressive symptoms or religiosity. Second, none of the biomarkers were normally distributed, and two of the biomarkers (IL4 and IL-12) could not be normalized with log transformation, factors which may have also influenced our results.

Third, the trial population included some participants whose MDD symptoms were only mild in severity. The findings may have been quite different had only participants with severe major depression been included. Fourth, treatment was delivered remotely by telephone, which may not have the same results as in-person treatment. However, recent evidence on CBT delivered in primary care suggests there is little difference in efficacy and that adherence may be better when therapy is delivered by telephone [59] [60]. Finally, many statistical comparisons were conducted to compare RCBT vs. CCBT on each of the 12 stress biomarkers in the ITT analysis and per-protocol analyses, as well as to test the moderating effects of religiosity and the effects of baseline religiosity on outcomes, increasing the likelihood of a Type 1 error. We chose to use a traditional significance level of 0.05 because of the exploratory nature of these analyses and the relatively small sample (which was not powered to detect changes in biomarker levels). Had we corrected our p-value for multiple comparisons the significance level would have been closer to 0.001 .

Nevertheless, the study also has a number of strengths. First, it was a multi-site randomized clinical trial conducted on the East and West coasts of the US that tested reasonable hypotheses based on the existing literature. Second, the interventions were structured and manual-based, administered by experienced therapists, and were administered in a standard dose (ten 50-minute sessions). Third, we diagnosed MDD using a structured psychiatric interview (MINI) and examined changes in depressive symptoms using a standard measure that is widely used in clinical trials of depression in primary care (BDI-II). Fourth, we measured religiosity in a comprehensive manner that is seldom done in studies of this nature. Fifth, we assessed a wide range of stress biomarkers known to be associated with depressive disorder and often found to be responsive to treatment. Finally, our use of mixed effects growth curve models enabled us to make maximum use of the available data.

\section{Conclusion}

Neither RCBT nor CCBT were consistently effective in reducing pro-inflammatory cytokines, increasing antiinflammatory cytokines, or reducing stress hormones in this sample of persons with chronic medical illness and major depressive disorder. The only exception was that CCBT had a greater impact on reducing the pro-inflammatory cytokine IL-6 in those with low religiosity, while RCBT seemed to have a greater effect on IL-6 in those with higher religiosity. Religiosity, however, predicted an increase in pro-inflammatory cytokines and the stress hormone cortisol over time independent of treatment group, which was not expected. Whether these findings are due to chance, given the multiple statistical comparisons, or due to the trial design will need to be determined by future research that seeks to replicate these results. 


\section{Funding}

Funding support provided by the John Templeton Foundation.

\section{References}

[1] Howren, M.B., Lamkin, D.M. and Suls, J. (2009) Associations of Depression with C-Reactive Protein, Il-1, and Il-6: A Meta-Analysis. Psychosomatic Medicine, 71, 171-186. http://dx.doi.org/10.1097/PSY.0b013e3181907c1b

[2] Hestad, K.A., Tonseth, S., Stoen, C.D., Ueland, T. and Aukrust, P. (2003) Raised Plasma Levels of Tumor Necrosis Factor Alpha in Patients with Depression: Normalization during Electroconvulsive Therapy. Journal of Electroconvulsive Therapy, 19, 183-188.

[3] Guglu, C., Kara, S.H., Caliyurt, O., Vardar, E. and Abay, E. (2003) Increased Serum Tumor Necrosis Factor-Alpha Levels and Treatment Response in Major Depressive Disorder. Psychopharmacology, 170, 429-433.

http://dx.doi.org/10.1007/s00213-003-1566-z

[4] Leonard, B.E. and Myint, A. (2009) The Psychoneuroimmunology of Depression. Human Psychopharmacology, 24, 165-175. http://dx.doi.org/10.1002/hup.1011

[5] Zorrilla, E.P., Luborsky, L., McKay, J.R., Rosenthal, R., Houldin, A., Tx, A., McCorkle, R., Seligman, D.A. and Schmidt, K. (2001) The Relationship of Depression and Stressors to Immunoloigcal Assays: A Meta-Analytic Review. Brain, Behavior, and Immunity, 15, 199-226. http://dx.doi.org/10.1006/brbi.2000.0597

[6] Miller, A.H. (1998) Neuroendocrine and Immune System Interactions in Stress and Depression. Psychiatric Clinics of North America, 21, 443-463. http://dx.doi.org/10.1016/S0193-953X(05)70015-0

[7] Evans, D.L., Ten have, T.R., Douglas, S.D., Gettes, D.R., Morrison, M., Chiappini, M.S., et al. (2002) Association of Depression with Viral Load, CD8 T Lymphocytes, and Natural Killer Cells in Women with HIV Infection. American Journal of Psychiatry, 159, 1752-1759. http://dx.doi.org/10.1176/appi.ajp.159.10.1752

[8] Thaker, P.H., Lutgendorf, S.K. and Sood, A.K. (2007) The Neuroendocrine Impact of Chronic Stress on Cancer. Cell Cycle, 6, 430-433. http://dx.doi.org/10.4161/cc.6.4.3829

[9] Lutgendorf, S.K., DeGeest, K., Sung, C.Y., Arevalo, J.M., Penedo, F. and Lucci III, J. (2009) Depression, Social Support, and Beta-Adrenergic Transcription Control in Human Ovarian Cancer. Brain, Behavior, \& Immunity, 23, 176183. http://dx.doi.org/10.1016/j.bbi.2008.04.155

[10] Zautra, A.J., Yocum, D.C., Villanueva, I., Smith, B., Davis, M.C., Attrep, J. and Irwin, M. (2004) Immune Activation and Depression in Women with Rheumatoid Arthritis. Journal of Rheumatology, 31, 457-463.

[11] Irwin, M.R. and Miller, A.H. (2007) Depressive Disorders and Immunity: 20 Years of Progress and Discovery. Brain, Behavior, and Immunity, 21, 374-383. http://dx.doi.org/10.1016/j.bbi.2007.01.010

[12] Hannestad, J., DellaGiola, N. and Bloch, M. (2011) The Effect of Antidepressant Medication Treatment on Serum Levels of Inflammatory Cytokines: A Meta-Analysis. Neuropsychoharmacology, 36, 2452-2459. http://dx.doi.org/10.1038/npp.2011.132

[13] Castanon, N., Leonard, B.E., Neveu, P.J. and Yirmiya, R. (2002) Effects of Antidepressants on Cytokine Production and Actions. Brain, Behavior, and Immunity, 16, 569-574. http://dx.doi.org/10.1016/S0889-1591(02)00008-9

[14] Dahl, J., Ormstad, H., Aas, H.C.D., Malt, U.F., Bendtz, L.T., Sandvik, L., Brundin, L. and Andreassen, O.A. (2014) The Plasma Level of Various Cytokines Are Increased during Ongoing Depression and Are Reduced to Normal Levels after Recovery. Psychoneuroendocrinology, 45, 77-86. http://dx.doi.org/10.1016/j.psyneuen.2014.03.019

[15] van Middendorp, H., Geenen, R., Sorbi, M.J., van Doornen, L.J. and Bijlsma, J.W. (2009) Health and Physiological Effects of an Emotional Disclosure Intervention Adapted for Application at Home: A Randomized Clinical Trial in Rheumatoid Arthritis. Psychotherapy \& Psychosomatics, 78, 145-151. http://dx.doi.org/10.1159/000206868

[16] Antoni, M.H., Lechner, S., Diaz, A., Vargas, S., Holley, H., Phillips, K., McGregor, B., Carver, C.S. and Blomberg, B. (2009) Cognitive Behavioral Stress Management Effects on Psychosocial and Physiological Adaptation in Women Undergoing Treatment for Breast Cancer. Brain, Behavior, and Immunity, 23, 580-591. http://dx.doi.org/10.1016/j.bbi.2008.09.005

[17] Roberts, A.D.L., Papadopoulos, A.S., Wessely, S., Chalder, T. and Cleare, A.J. (2009) Salivary Cortisol Output before and after Cognitive Behavioral Therapy for Chronic Fatigue Syndrome. Journal of Affective Disorders, 115, $280-286$. http://dx.doi.org/10.1016/j.jad.2008.09.013

[18] Pew Forum (2007) US Religious Landscape Survey. http://religions.pewforum.org/

[19] The Gallup Poll (2009) State of the States: Importance of Religion. http://www.gallup.com/poll/114022/state-states-importance-religion.aspx

[20] Pargament, K. (1997) The Psychology of Religion and Coping. Guilford Press, New York. 
[21] Koenig, H.G. (1998) Religious Beliefs and Practices of Hospitalized Medically Ill Older Adults. International Journal of Geriatric Psychiatry, 13, 213-224. http://dx.doi.org/10.1002/(SICI)1099-1166(199804)13:4<213::AID-GPS755>3.0.CO;2-5

[22] Koenig, H.G., Cohen, H.J., Blazer, D.G., Pieper, C., Meador, K.G., Shelp, F., Goli, V. and DiPasquale, R. (1992) Religious Coping and Depression in Elderly Hospitalized Medically Ill Men. American Journal of Psychiatry, 149, 16931700. http://dx.doi.org/10.1176/ajp.149.12.1693

[23] Koenig, H.G. (2007) Religion and Remission of Depression in Medical Inpatients with Heart Failure/Pulmonary Disease. Journal of Nervous and Mental Disease, 195, 389-395.

[24] Koenig, H.G., George, L.K. and Peterson, B.L. (1998) Religiosity and Remission of Depression in Medically Ill Older Patients. American Journal of Psychiatry, 155, 536-542. http://dx.doi.org/10.1176/ajp.155.4.536

[25] Koenig, H.G., Cohen, H.J., George, L.K., Hays, J.C., Larson, D.B. and Blazer, D.G. (1997) Attendance at Religious Services, Interleukin-6, and Other Biological Indicators of Immune Function in Older Adults. International Journal of Psychiatry in Medicine, 27, 233-250. http://dx.doi.org/10.2190/40NF-Q9Y2-0GG7-4WH6

[26] Lutgendorf, S.K., Russell, D., Ullrich, P., Harris, T.B. and Wallace, R. (2004) Religious Participation, Interleukin-6, and Mortality in Older Adults. Health Psychology, 23, 465-475. http://dx.doi.org/10.1037/0278-6133.23.5.465

[27] King, D.E., Mainous III, A.G. and Pearson, W.S. (2002) C-Reactive Protein, Diabetes, and Attendance at Religious Services. Diabetes Care, 25, 1172-1176. http://dx.doi.org/10.2337/diacare.25.7.1172

[28] Bellinger, D.L., Berk, L.S., Koenig, H.G., Daher, N., Pearce, M.J., Robins, C.J., Nelson, B., Shaw, S.F., Cohen, H.J. and King, M.B. (2014) Religious Involvement, Inflammatory Markers and Stress Hormones in Major Depression and Chronic Medical Illness. Open Journal of Psychiatry, 4, 335-352. http://dx.doi.org/10.4236/ojpsych.2014.44040

[29] Dedert, E.A., Studts, J.L., Weissbecker, I., Salmon, P.G., Banis, P.L. and Sephton, S.E. (2004) Private Religious Practice: Protection of Cortisol Rhythms among Women with Fibromyalgia. International Journal of Psychiatry in Medicine, 34, 61-77. http://dx.doi.org/10.2190/2Y72-6H80-BW93-U0T6

[30] Tartaro, J., Luecken, L.J. and Gunn, H.E. (2005) Exploring Heart and Soul: Effects of Religiosity/Spirituality and Gender on Blood Pressure and Cortisol Stress Responses. Journal of Health Psychology, 10, 753-766. http://dx.doi.org/10.1177/1359105305057311

[31] Ironson, G., Soloman, G.F., Balbin, E.G., O’Cleirigh, C., George, A., Kumar, M., et al. (2002) The Ironson-Woods Spirituality/Religiousness Index Is Associated with Long Survival, Health Behaviors, Less Distress, and Low Cortisol in People with HIV/AIDS. Annals of Behavioral Medicine, 24, 34-48. http://dx.doi.org/10.1207/S15324796ABM2401_05

[32] Carrico, A.W., Ironson, G., Antoni, M.H., Lechner, S.C., Duran, R.E., Kumar, M., et al. (2006) A Path Model of the Effects of Spirituality on Depressive Symptoms and 24-h Urinary-Free Cortisol in HIV-Positive Persons. Journal of Psychosomatic Research, 61, 51-58. http://dx.doi.org/10.1016/j.jpsychores.2006.04.005

[33] Chan, C.L., Ho, R.T., Lee, P.W., Cheng, J.Y., Leung, P.P., Foo, W., et al. (2006) A Randomized Controlled Trial of Psychosocial Interventions Using the Psychophysiological Framework for Chinese Breast Cancer Patients. Journal of Psychosocial Oncology, 24, 3-26. http://dx.doi.org/10.1300/J077v24n01_02

[34] Bellinger, D.L., Berk, L.S., Koenig, H.G., Daher, N., Pearce, M.J., Robins, C.J., Nelson, B., Shaw, S.F., Cohen, H.J. and King, M.B. (2014) Religious Involvement, Inflammatory Markers and Stress Hormones in Major Depression and Chronic Medical Illness. Open Journal of Psychiatry, 4, 335-352. http://dx.doi.org/10.4236/ojpsych.2014.44040

[35] Pace, T.W., Negi, L.T., Adame, D.D., Cole, S.P., Sivilli, T.I., Brown, T.D., et al. (2009) Effect of Compassion Meditation on Neuroendocrine, Innate Immune and Behavioral Responses to Psychosocial Stress. Psychoneuroendocrinology, 34, 87-98. http://dx.doi.org/10.1016/j.psyneuen.2008.08.011

[36] Witek-Janusek, L., Albuquerque, K., Chroniak, K.R., Chroniak, C., Durazo-Arvizu, R. and Mathews, H.L. (2008) Effect of Mindfulness Based Stress Reduction on Immune Function, Quality of Life and Coping in Women Newly Diagnosed with Early Stage Breast Cancer. Brain, Behavior, and Immunity, 22, 969-981. http://dx.doi.org/10.1016/j.bbi.2008.01.012

[37] Sudsuang, R., Chentanez, V. and Veluvan, K. (1991) Effect of Buddhist Meditation on Serum Cortisol and Total Protein Levels, Blood Pressure, Pulse Rate, Lung Volume and Reaction Time. Physiology \& Behavior, 50, 543-548. http://dx.doi.org/10.1016/0031-9384(91)90543-W

[38] Walton, K.G., Fields, J.Z., Levitsky, D.K., Harris, D.A., Pugh, N.D., Schneider, R.H., et al. (2004) Lowering Cortisol and CVD Risk in Postmenopausal Women: A Pilot Study Using the Transcendental Meditation Program. Annals of the New York Academy of Sciences, 1032, 211-215. http://dx.doi.org/10.1196/annals.1314.023

[39] Jin, P. (1992) Efficacy of Tai Chi, Brisk Walking, Meditation, and Reading in Reducing Mental and Emotional Stress. Journal of Psychosomatic Research, 36, 361-370. http://dx.doi.org/10.1016/0022-3999(92)90072-A

[40] Curiati, J.A., Bocchi, E., Freire, J.O., Arantes, A.C., Braga, M., Garcia, Y., et al. (2005) Meditation Reduces Sympa- 
thetic Activation and Improves the Quality of Life in Elderly Patients with Optimally Treated Heart Failure: A Prospective Randomized Study. Journal of Alternative and Complementary Medicine, 11, 465-472.

http://dx.doi.org/10.1089/acm.2005.11.465

[41] Koenig, H.G., Pearce, M.J., Nelson, B., Shaw, S.F., Robins, C.J., Daher, N., Cohen, H.J., Berk, L.S., Bellinger, D., Pargament, K.I., Rosmarin, D.H., Vasegh, S., Kristeller, J., Juthani, N., Nies, D. and King, M.B. (2015) Religious vs. Conventional Cognitive-Behavioral Therapy for Major Depression in Persons with Chronic Medical Illness. Journal of Nervous and Mental Disease, 203, 243-251. http://dx.doi.org/10.1097/NMD.0000000000000273

[42] Sheehan, B.V., Lecrubier, Y., Sheehan, K.H., Amorim, P., Janavs, J., Weiller, E., et al. (1998) The Mini International Neuropsychiatric Interview (MINI): The Development and Validation of Structured Diagnostic Psychiatric Interview for DSM-IV and ICD-10. Journal of Clinical Psychiatry, 59, 22-33.

[43] Beck, A.T., Ward, C.H., Mendelson, M., Mock, J. and Erbaugh, J. (1961) An Inventory for Measuring Depression. Archives of General Psychiatry, 4, 561-571. http://dx.doi.org/10.1001/archpsyc.1961.01710120031004

[44] Koenig, H.G. (1996) An Abbreviated Mini-Mental State Exam for Medically Ill Elders. Journal of the American Geriatrics Society, 44, 215-216. http://dx.doi.org/10.1111/j.1532-5415.1996.tb02449.x

[45] Beck, A.T., Rush, J., Shaw, B.F. and Emery, G. (1979) Cognitive Therapy of Depression. Guilford Press, New York.

[46] Pearce, M.J., Koenig, H.G., Robins, C.J., Nelson, B., Shaw, S.F., Cohen, H.J. and King, M.B. (2015) Religiously-Integrated Cognitive Behavioral Therapy: A New Method of Treatment for Major Depression in Patients with Chronic Medical Illness. Psychotherapy, 52, 56-66. http://dx.doi.org/10.1037/a0036448

[47] Religious Cognitive Behavioral Therapy Manuals (2014) Duke University Center for Spirituality, Durham, NC. Theology and Health. Manuals and Workbooks at: http://www.spiritualityandhealth.duke.edu/index.php/religious-cbt-study/therapy-manuals

[48] Koenig, H.G., Meador, K.G. and Parkerson, G. (1997) Religion Index for Psychiatric Research. American Journal of Psychiatry, 154, 885-886. http://dx.doi.org/10.1176/ajp.154.6.885b

[49] Hoge, D.R. (1972) A Validated Intrinsic Religious Motivation Scale. Journal for the Scientific Study of Religion, 11, 369-376. http://dx.doi.org/10.2307/1384677

[50] Underwood, L.G. and Teresi, J.A. (2002) The Daily Spiritual Experiences Scale: Development, Theoretical Description, Reliability, Exploratory Factor Analysis, and Preliminary Construct Validity Using Health-Related Data. Annals of Behavioral Medicine, 24, 22-33. http://dx.doi.org/10.1207/S15324796ABM2401_04

[51] Hlatky, M.A., Boineau, R.E., Higginbotham, M.B., Lee, K.L., Mark, D.B., Califf, R.M., Cobb, F.R. and Pryor, D.B. (1989) A Brief Self-Administered Questionnaire to Determine Functional Capacity (The Duke Activity Status Index). American Journal of Cardiology, 64, 651-654. http://dx.doi.org/10.1016/0002-9149(89)90496-7

[52] Charlson, M.E., Pompei, P., Ales, K.L. and Mackenzie, C.R. (1987) A New Method of Classifying Prognostic Comorbidity in Longitudinal Studies: Development and Validation. Journal of Chronic Disease, 40, 373-383. http://dx.doi.org/10.1016/0021-9681(87)90171-8

[53] Linn, B., Linn, M. and Gurel, L. (1968) Cumulative Illness Rating Scale. Journal of the American Geriatrics Society, 16, 622-626. http://dx.doi.org/10.1111/j.1532-5415.1968.tb02103.x

[54] Myint, A.M., Leonard, B.E., Steinbusch, H.W. and Kim, Y.K. (2005) Th1, Th2, and Th3 Cytokine Alterations in Major Depression. Journal of Affective Disorders, 88, 167-173. http://dx.doi.org/10.1016/j.jad.2005.07.008

[55] Dowlati, Y., Herrmann, N., Swardfager, W., Liu, H., Sham, L., Reim, E.K. and Lanctôt, K.L. (2010) A Meta-Analysis of Cytokines in Major Depression. Biological Psychiatry, 67, 446-457.

http://dx.doi.org/10.1016/j.biopsych.2009.09.033

[56] Veith, R.C., Lewis, N., Linares, O.A., Barnes, R.F., Raskind, M.A., Villacres, E.C., Murburg, M.M., Ashleigh, E.A., Castillo, S., Peskind, E.R., Pasculay, M. and Halter, J.B. (1994) Sympathetic Nervous System Activity in Major Depression. Basal and Desipramine-Induced Alterations in Plasma Norepinephrine Kinetics. Archives of General Psychiatry, 51, 411-422. http://dx.doi.org/10.1001/archpsyc.1994.03950050071008

[57] Wampold, B.E., Mondin, G.W., Moody, M., Stich, F., Benson, K. and Ahn, H. (1997) A Meta-Analysis of Outcome Studies Comparing Bona Fide Psychotherapies: Empirically, “All Must Have Prizes.” Psychological Bulletin, 122, 204-215. http://dx.doi.org/10.1037/0033-2909.122.3.203

[58] Zorrilla, E.P., Luborsky, L., McKay, J.R., Rosenthal, R., Houldin, A., Tax, A., McCorkle, R., Seligman, D.A. and Schmidt, K. (2001) The Relationship of Depression and Stressors to Immunological Assays: A Meta-Analytic Review. Brain, Behavior, and Immunity, 15, 199-226. http://dx.doi.org/10.1006/brbi.2000.0597

[59] Mohr, D.C., Ho, J., Duffecy, J., Reifler, D., Sokol, L., Burns, M.N., et al. (2012) Effect of Telephone-Administered vs. Face-to-Face Cognitive Behavioral Therapy on Adherence to Therapy and Depression Outcomes among Primary Care Patients: A Randomized Trial. Journal of the American Medical Association, 307, 2278-2285.

http://dx.doi.org/10.1001/jama.2012.5588 
[60] Kalapatapu, R.K., Ho, J., Cai, X., Vinogradov, S., Batki, S.L. and Mohr, D.C. (2014) Cognitive-Behavioral Therapy in Depressed Primary Care Patients with Co-Occurring Problematic Alcohol Use: Effect of Telephone-Administered vs. Face-to-Face Treatment-A Secondary Analysis. Journal of Psychoactive Drugs, 46, 85-92.

http://dx.doi.org/10.1080/02791072.2013.876521 